\title{
¿DERECHA, IZQUIERDA O CENTRO? \\ SOBRE LA LEGITIMACION DE LOS PARTIDOS \\ Y COALICIONES EN EL SUR DE EUROPA *
}

POR

GIUSEPPE DI PALMA

Universidad de Florencia

He indicado en las páginas introductoras que las opciones de coalición en la transición en curso pueden reducirse por simplificación a cuatro, según que supongan gobiernos monocolor o de coalición y la alternancia o la continuidad en el tiempo.

Además he apuntado que se tiende a pretender la formación de coaliciones extensas, $o$ incluso sin alternancia y con origen en el centro político, cuando existe un problema recurrente de legitimidad del gobierno o del sistema político. Este tipo de coaliciones puede permitir mejor una supervivencia tolerable ${ }^{35}$, y si son empleadas hábilmente pueden incluso conseguir cierto grado de legitimación del sistema político.

Finalmente, he señalado que la adopción de coaliciones extensas y el uso que se hace de ellas dependen de las condiciones de transición que pueden cambiar de un país a otro y a tenor con el contexto histórico.

Pero antes de continuar con el análisis de las transiciones en el área mediterránea, he concluido que el paso a esquemas de alternancia tolerables por todos los partidos significativos es un signo positivo de que la cuestión de la legitimación de los partidos y coaliciones se encuentra en un estadio favorable.

A este respecto, ¿cuál es entonces el estado de nuestros países? Tres de ellos - Portugal, España y más claramente Italia - han adoptado una estrategia de transición que puede describirse adecuadamente como de coalición amplia (o extensa), a pesar de que en el gobierno se halle en realidad un solo partido. El hecho, sin embargo, es que esta opción, aun respondiendo a un problema común de legitimación, muestra diferentes posibilidades de éxito. Por-

* La primera parte de este artículo se publicó en el número 4 de esta revista, páginas 125 a 145 .

${ }^{35}$ G. di Palma, Surviving Without Governing, cit., cap. 7 . 
tugal, con un juego político aún cerrado a los extremos, permanece todavía muy lejos de la alternancia pacífica. España se encuentra quizá más próxima a ella; mientras que Italia, con un juego abierto a todos pero con apuestas y fines en último término diferentes, no se presta aún a fáciles predicciones sobre tiempo y resultados. Lo mismo puede decirse en cuanto a predicciones respecto a Grecia, donde los éxitos conseguidos hasta el momento por una estrategia gaullista francamente lejana de la sincrética antes mencionada y de más arriesgada ejecución, optando en realidad desde el comienzo por la hipótesis de la alternancia, no eliminan de hecho el riesgo de que el problema de la legitimidad, temporalmente adormecido y domesticado, aflore si se pone en práctica la hipótesis en el futuro.

Portugal.-El caso portugués, en mi opinión, es el más claro y de interpretación más simple. El hecho de un sistema de partidos con pluralismo limitado, o sea, la presencia de no más de cuatro partidos relevantes, no constituye elemento suficiente para un pluralismo moderado en los comportamientos $\mathrm{y}$, por tanto, una tolerable alternancia derecha-izquierda. Dos son los problemas: la naturaleza de los dos partidos en los extremos y la distribución de las preferencias electorales a lo largo del abanico partidista. Si el comportamiento centrífugo de la extrema izquierda y del Partido Social Democrático de Sa Carneiro consiguió un generoso 45 por 100 aproximado de los votos, no veo que exista un estímulo inmediato para desistir de tal comportamiento. Así, la coalición centrista, formada a comienzos del 78 , nació como reacción «faute de mieux» de la combinación de dos «partners» de tradición política heterogénea, cuya capacidad de atraer votos en sus respectivas alas es puesta en duda por la firme presencia de dos extremos deslegitimantes de fuerza casi igual que se anulan recíprocamente (la coalición DC nunca tuvo un problema tan serio a su derecha). Además, es indicativo del papel deslegitimante de los extremos el reciente comportamiento del PSD, en cuyo interior, luego del rechazo de cualquier hipótesis de coalición moderada a la caída del monocolor de Soares y luego de un eclipse temporal de Sa Carneiro, las presiones para que el partido se ponga a la cabeza de un «nuevo inicio» en clave revanchista han alcanzado hoy el punto álgido. La propuesta de recomenzar todo desde el principio se mueve en tres direcciones:

1. Nueva limitación o derogación de las reformas sociales introducidas por las Fuerzas Armadas.

2. Revocación de los propios elementos socialistas de la Constitución impuestos a los constituyentes por la tutela de los militares.

3. Cesación del papel tutelar asignado por la Constitución a las Fuerzas Armadas y, con ellas, al Consejo de la Revolución. Depuración final de los «capitanes de abril».

$\mathrm{Si}$ bien estas propuestas tienen origen en el defecto de nacimiento de la democracia portuguesa (el choque de dos estrategias opuestas de legitimación), no es precisamente volviendo simplemente atrás como el defecto puede arreglarse. Tampoco los socialistas, ya expuestos a los chantajes de la izquierda y 
a los condicionamientos descalificadores de los «partners» de gobierno, tienen interés en seguir este juego. En cualquier caso, aun asumiendo que las ambiciones electorales y estratégicas del PSD se vean frustradas, el hecho es que el problema de la legitimidad no sólo de los partidos y coaliciones, sino también del ordenamiento constitucional mismo, permanece abierto. Coaliciones de centro, de vida difícil, parecen, por tanto, la respuesta más probable, siempre que algunos elementos de las Fuerzas Armadas no se vean tentados de dar un giro de tipo presidencial y nuevamente tutelar a la evolución portuguesa. Si las coaliciones de centro fallan, el futuro, en un país económicamente tan dependiente del Occidente, será todavía menos prometedor. Que pueden fallar lo demuestra la caída del gobierno PSP.CDS en el momento de enviar este ensayo a la imprenta.

\section{Cuadro 1}

ELECCIONES DE LA ASAMBLEA CONSTITUYENTE (ABRIL DE 1975) $Y$ DE LA ASAMBLEA REPUBLICANA (ABRIL DE 1976)

(EN PORCENTAJES)

\begin{tabular}{|c|c|c|}
\hline & 1975 & 1976 \\
\hline Centro Democrático Social .... & 7,6 & 15,9 \\
\hline Partido Popular Democrático ${ }^{1}$ & 26,4 & 24,0 \\
\hline 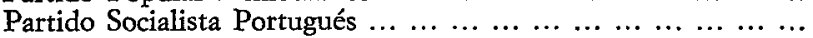 & 37,9 & 35,0 \\
\hline $\begin{array}{l}\text { Partido Comunista Portugués } \ldots \\
\ldots\end{array}$ & 12,5 & 14,6 \\
\hline 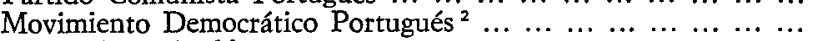 & 4,1 & - \\
\hline 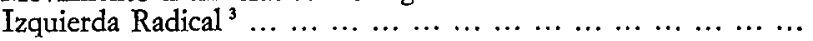 & 4,0 & 4,8 \\
\hline
\end{tabular}

1 Ahora Partido Social Democrático.

2 Los votos convergieron en el PCP en las elecciones de 1976.

3 De seis a siete agrupaciones diversas.

España.-Con dos partidos en los extremos con menos de la mitad de los votos que sus colegas portugueses y con la UCD y el PSOE (que incluye ya el partido socialista de Tierno Galván) elegidos a partes iguales por aproximadamente dos tercios de los votantes, el sistema partidista español aparece especialmente dispuesto para una alternativa derecha-izquierda centralizada sobre dos alas moderadas. La presencia de los reagrupamientos regionales relevantes no contradice la naturaleza numéricamente limitada del pluralismo de partidos. De hecho, la cuestión es que tanto la Minoría Catalana como, sobre todo, el Partido Nacionalista Vasco (que es el más difícil de los dos) son precisamente organizaciones regionales que no obstante su postura moderada en lo que no toca al regionalismo, contempla su papel desde el punto de vista regionalista, sustrayéndose, por tanto, a una ubicación derecha-izquierda y mostrándose por ahora poco o nada inclinados a estrategias de coalición a nivel de gobierno nacional ${ }^{36}$. Tampoco contradice el pluralismo limitado el hecho de que existan un gran número de partidos sin escaños en el Parlamento, que, en

${ }^{36}$ Sobre los problemas derivados de la ubicación de los partidos regionales-religiosos-lingüísticos en un sistema nacional de partidos, véase G. di Palma, ibíd., cap. 6. 
particular, el ámbito ocupado por Alianza y UCD sea un verdadero laberinto de agrupaciones y facciones conservadoras, liberales, católicos y socialdemócratas de diversos tipos. En mi opinión, en combinación y con varios cambios, dicho campo debería continuar controlado por los partidos que lo ocupan ahora, mientras que los partidos nuevos (como, por ejemplo, Acción Ciudadana Liberal, fundado recientemente por Aré́lza), en el caso de que intentaran actuar como entidades diferenciadas, deberán tener una vida precaria.

La razón de esta consolidación y simplificación del espectro moderado-conservador, así como, cosa más importante, la razón por la cual, al mismo tiempo, España podría moverse en un futuro próximo hacia un sistema con credibilidad de alternativa derecha-izquierda (la razón, en suma, por la cual a un pluralismo limitado en el número puede añadirse un pluralismo moderado en el comportamiento), es la forma de dirigir la denominada política de consenso en materia de reformas sociales y constitucionales, dirección tendente a actuar de tal modo que el nuevo sistema de partidos salga rápidamente y bien de la fase de legitimación. Una comparación con la transición italiana de la posguetra, de otra parte similar en muchos aspectos, puede servir para enfocar la cuestión. En Italia, el sistema de partidos nació, no obstante la común resistencia al fascismo, carente de legitimación y consecuentemente polarizado a la izquierda. A ello contribuyó, por lo menos, el contexto internacional, contra el cual poco pudieron los recíprocos arreglos constitucionales («svolta di Salerno», Gobierno de Unidad Nacional, voto comunista sobre el artículo 7, adopción de una constitución garantista mutuamente aceptable), cuyo resultado fue más bien una especie de «compromiso incierto», un incómodo «modus vivendi» contra prevaricaciones recíprocas ${ }^{37}$. Además, el hecho de que el sistema de partidos se polarizase también a la derecha con el derrocamiento del fascismo y la expulsión de la monarquía y, por tanto, con la presencia de fuerzas exteriores al espectro constitucional por aquel lado, impidió a la DC buscar una contribución al gobierno en esta dirección. De ahí la necesidad de coaliciones centristas.

En España, por otra parte, el partido gubernamental no se enfrenta con un partido comunista de guerra fría. La oposición principal es, por el contrario, un partido socialista sin ninguno de los peculiares problemas electorales, de legitimación y de alianza que acosan a los socialistas italianos. Además, pasada con halagadores éxitos la fase inicial y más difícil de «legitimación-retroactiva», el impedimento contra el uso de fuerzas en el área de Alianza Popular hacia ciertos pactos de gobierno tiende a debilitarse -al menos, ya no es automático- . Todo esto permite a UCD llevar a cabo un doble juego: por un lado, un juego de coalición que la permita en el futuro dirigir un espectro político que vaya desde una derecha en el fondo constitucionalizada hasta un centro-izquier-

${ }^{37}$ En efecto, comunistas y democristianos se presentaron a la Asamblea Constituyente con proyectos constitucionales totalmente distintos: el PCI, con un modelo centralizado de supremacía parlamentaria, de inspiración jacobina; la DC, con un modelo garantista de controles y equilibrios, de derivación social-católica. Véase G. di Palma, Risposti parlamentari alla crisi del regime: un problema de instituzionalizzacione, en L. Graziano y S. Tarrow (a cargo de), La crisi italiana, Turín, Einaudi, 1978 (en prensa). 
da; por el otro, un juego constitucional aún hoy basado en la «política de consenso».

Mientras, en definitiva, en Italia las coaliciones de centro sin cambios periódicos fueron impuestas por un sistema de partidos sin legitimación, y, por tanto, polarizado, cuyos defectos podía mitigar, pero no eliminar, un compromiso constitucional negativo ${ }^{38}$, en España el principio de cambio periódico es más verosímil desde la perspectiva de un sistema moderado de partidos, sostenido por un consenso constitucional más positivo. En Italia la falta de una alternativa verosímil ha retrasado un salto cualitativo del compromiso constitucional; en España el cambio periódico real de gobierno no debería servir de obstáculo para la continuación de políticas constitucionales colectivas.

Naturalmente, seguimos hablando de esquemas futuros, y el esquema del cambio periódico sigue siendo de delicada puesta en práctica y ejecución. De hecho, reconocer los méritos del modo en que se ha dirigido el proceso de legitimación de la España democrática no niega, sino, por el contrario, implica precisamente la existencia de un problema de legitimidad. La misma elección de un sistema pluralista abierto (no podía ser de otro modo), comporta un costo potencial de polarización en las alas extremas a pesar de los incentivos para que se constitucionalicen. Aunque puede decirse que el PCE se ha mostrado más gubernamental que Suárez en el debate constitucional, sigue siendo un partido comunista con vocación todavía no definida $\mathrm{y}$, de cualquier modo, es considerado como tal por los otros partidos, con razón o sin ella.

Si bien Alianza Popular rechaza etiquetas nostálgicas y considera cualquier modelo autoritario superado para la España actual, es todavía el único de los cuatro partidos nacionales que, sin romper abiertamente, se ha mantenido al margen de la política de consenso constitucional, invocando a menudo soluciones «fuertes» en el debate constitucional y culminando su propia actuación con un voto de abstención destinado a reverdecer dudas. Así se comprende que derecha e izquierda se muestren aún remisos a formar coaliciones de uno u otro signo. Mientras una buena parte del partido gubernamental se muestra fría ante la perspectiva de una gran derecha promovida por Alianza, la alternativa socialista invocada por el PSOE se detiene en el umbral de una alianza con los comunistas, alianza que, por otra parte, estos mismos descartan.

Pero situado todo esto en su justo término, conviene, sin embargo, insistir en que la alternativa presenta en España un potencial ganador que es inusual en los otros países. El que así sea está implícito en las estrategias recíprocas de la UCD y del PSOE, estrategias de estrecha colaboración constitucional acompañadas (ésta es la cuestión) por una cuidadosa preparación de las instituciones de gobierno y de los correspondientes canales de acceso, de modo que se aseguren mutuamente la tajada más grande en un juego futuro de recíproca sustitución en el gobierno. De aquí nace la acusación hecha por los partidos extremos de que se tiende hacia un sistema bipartidista a costa de ellos.

Vista desde esta perspectiva, la exclusión de los partidos extremos no contradice el designio final de la alternancia, sino que puede ser comprendida como

${ }^{38} \mathrm{La}$ oposición del PSOE a la monarquía no suscita problema alguno de fidelidad. Se trata de una posición de principio que no es del todo incompatible con la voluntad de los socialistas de trabajar con la monarquía. 
una opción contingente, adecuada además para acelerar la constitucionalización de aquéllos y, por tanto, para comprobación de ese mismo designio. Que, por ejemplo, UCD se presente como fuerza centrista en respuesta a las pretensiones de Alianza Popular no significa necesariamente que haya elegido un gobierno a la italiana o que históricamente se haya resignado a ello; por el contrario, la postura de UCD puede ser útil para proyectar una imagen electoral de partido que los electores tienden a primar en un sistema de pluralismo moderado, además de para establecer que cualquier coalición tiende a centrarse en torno a su eje interior en sistemas de cambio periódico verosímil.

Esta capacidad de atracción del eje interior, si es probable dentro de la derecha debería serlo igualmente dentro de la izquierda. También es cierto que, como ya he dicho, el PCE, erigido en defensor incorruptible de una transición pactada, la proyecta en un método futuro de gobierno que rehúsa el cambio periódico. $Y$ se trata, como sabemos, de un comportamiento dirigido a conseguir legitimidad y, al mismo tiempo, a preparar al partido para una larga marcha a través de las instituciones y a una estrategia de presencia social y de cambios políticos bien aprendida de los comunistas italianos. Pero el llamamiento a grandes coaliciones como método duradero de gobierno, que es ya fuente de dudas, pierde justificación cuando el país, como es probable, salga bien de la fase inicial. En suma, la propuesta de los comunistas españoles carece de persuasividad: es difícil imaginar al PCE como probable candidato, o más aún, como guía de futuras coaliciones amplias que no sean necesarias. Es más fácil imaginar un PCE constitucionalizado y que a través de adaptaciones haya madurado en la lógica de una alternativa socialista ${ }^{39}$.

Está claro que con los comunistas italianos las cosas son mucho más complejas.

CUADRO 2

ELECCIONES DEL CONGRESO (JUNIO 1977)

\begin{tabular}{|c|c|c|}
\hline & $\%$ votos & Escaños \\
\hline 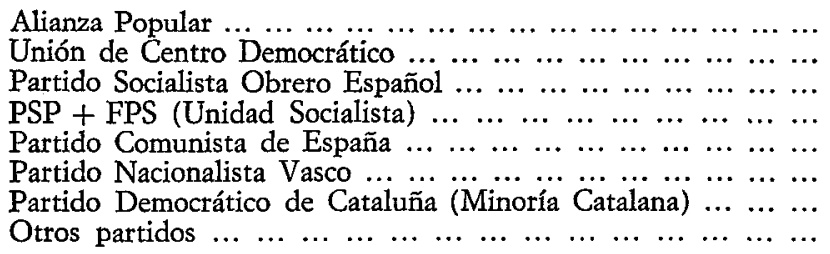 & $\begin{array}{r}8,4 \\
34,7 \\
29,2 \\
4,5 \\
9,2 \\
1,3 \\
3,0 \\
9,7\end{array}$ & $\begin{array}{r}16 \\
165 \\
118 \\
6 \\
20 \\
8 \\
11 \\
6\end{array}$ \\
\hline
\end{tabular}

${ }^{39}$ Considerando el conflicto abierto que ha surgido en el interior del PCE durante su reciente Congreso, se puede decir que la estrategia del partido no estaba definida del todo. La franqueza del debate (algo impensable también en el PCI) y las bases regionales del partido pueden producir que el problema de la composición y del papel de la extrema izquierda quede sin solución durante bastante tiempo. 
Italia.—¿Están los socialistas y los democristianos italianos en condiciones de convencer a sus comunistas para llevar a cabo un juego de cambio, suponiendo que sea ésta su estrategia preeminente para un futuro no lejano?

¿Están los comunistas interesados o al menos son susceptibles de ser llevados a este juego? ¿O es cierto, como ya he dicho, que la solución de la transición italiana, a pesar de sus aspectos transaccionales, sigue estando cada vez más incierta? A primera vista podrá parecer más fácil relegitimar un sistema de partidos y de coaliciones que ya existe y que opera en un marco democrático con una historia de décadas a sus espaldas. Pero ¿se trata verdaderamente de relegitimación? El término implica que la legitimidad hubiera existido en un período anterior, pero el hecho de que la DC y el PCI, aunque hayan demostrado atención reiterada a sus recíprocas adaptaciones, han seguido durante décadas un juego divergente - la DC ocupada en negar las credenciales democráticas del PCI, y éste ocupado en denunciar el derecho de las coaliciones centristas para gobernar - suscita dudas sobre la existencia de una legitimidad consolidada, por lo que resulta más correcto concluir que el problema de la legitimidad del sistema de partidos, así como el de la legitimidad de las coaliciones, siguen estando más abiertos que nunca lo han estado en treinta años de República.

He explicado por qué, a medida que mejora la imagen popular del PCI en los últimos años, mientras que la de los gobiernos DC se deteriora, aumentan, en lugar de disminuir, los alicientes para la convergencia. Pero el hecho de que las estrategias de un partido hacia el otro, elaboradas durante la emetgencia en curso, comporten un salto cualitativo respecto al pasado (¿cualitativo o cuantitativo?) no excluye que los objetivos últimos perseguidos por las dos partes sigan siendo divergentes. Para la DC y para los otros partidos constitucionales, incluidos los socialistas, se trata de legitimar en último término un marco clásico de gobierno parlamentario competitivo, aun cuando, más claramente ahora que en el pasado, se persiga el objetivo intentando convencer al PCI de sus ventajas e implicándolo en la responsabilidad de gobierno. Para el PCI, por otra parte, se trata principal y más simplemente de acreditarse como partido de gobierno. Deseo comprensible por un lado, $\epsilon$ specialmente después de treinta años de oposición, y a primera vista compatible con el de los otros partidos.

Cualquier partido aspira a gobernar lo más frecuente y confortablemente posible. Pero el PCI no es un partido cualquiera y su aspiración no es gobernar lo más a menudo posible, sino cuanto más tiempo posible. Así, mientras el objetivo de la DC es la legitimación del sistema de partidos y de coaliciones intercambiables, el del PCI es la hegemonía sobre los partidos y las coaliciones; y la hegemonía, a pesar de los esfuerzos comunistas por demostrar lo contrario, es un concepto que para los otros partidos no comprende la legitimidad democrática.

La divergencia de los objetivos finales aparece sobre todo en la propuesta del compromiso histórico con la que, repitiendo lo que he dicho en otro lugar, los comunistas quieren decir dos cosas ${ }^{40}$. Dicen que ninguna coalición de fuer-

${ }^{40} \mathrm{G}$. di Palma, Political Syncretism in Italy, cit. 
zas homogéneas, y por lo mismo limitadas, puede pretender gobernar por sí sola , aunque fuera en un contexto de cambio periódico en países como Italia, fragmentados política y socialmente y divididos por barreras históricas. De aquí la necesidad objetiva de gobernar juntos; de aquí la necesidad que tiene el PCI de abandonar estrategias más limitadas y rígidas de tipo frentepopular y de ampliar las alianzas a las fuerzas moderadas y a las capas sociales que los apoyan. En este sentido, la propuesta comunista reconoce y trata implícitamente de reconquistar los efectos estabilizadores de las viejas coaliciones dirigidas por la DC. De aquí, y del hecho de que la propuesta permite a la DC conservar su imagen centrista y popular, se deriva su capacidad de persuasión; capacidad, sin embargo, seriamente comprometida por el segundo aspecto de la propuesta.

De hecho, para los comunistas el compromiso histórico es muy diferente y mucho más que una alianza de emergencia, que responde a las necesidades reales y a los medios tácticos de situación política. Al proponer esto, los comunistas dicen también que por encima de las necesidades histórica o contingentemente impuestas, en el gobierno de coalición en un sistema que elimine distinciones coercitivas entre gobierno y oposición existe una virtud subjetiva y una ventaja de principios para los fines de un proyecto socialista. De este modo los comunistas ven en el compromiso no sólo una etapa obligada para el acceso al poder, sino también la prefiguración de una estrategia de gobierno y de penetración en la sociedad que sustituya a la persuasión, a la fusión de intereses y a la manipulación de un consenso «indiferente», tanto a la dictadura del proletariado, groseramente unilateral y sin resquicios, como, y ésta es la cuestión, al formalismo democrático del cambio periódico. Naturalmente, puesto que se trata de una estrategia aditiva, requiere el reconocimiento y la exaltación del pluralismo y de la diversidad; naturalmente, puesto que se invoca en el presente contexto democrático, la presentan como una estrategia democrática. $\mathrm{Y}$, por otra parte, no cabe dudar de que los dirigentes comunistas vean en ella una elevada expresión de la democracia participativa y la única solución para la construcción del socialismo (no de la socialdemocracia) en un contexto democrático ya consolidado. Pero pluralismo y democracia adquieren en esta teorización, como en muchas otras teorizaciones de una democracia inclusiva y de participación, un significado mucho más repelente, muy ajeno a los preceptos y a la práctica política occidental, que son teorizados no como un conflicto «checks and balances» *, gobierno de mayorías limitadas, coaliciones ocasionales y cambiantes, sino precisamente como un consenso, cooptación, inclusividad, bloques y concentraciones. De ello se infiere que el manejo de alianzas solidarias y amplias requiera un partido fuerte que concentre y hegemonice los distintos intereses. El motivo no es tanto el interés, como en el caso de la DC, cuya hegemonía no ha sido nunca invocada científicamente por sus escépticos intérpretes, sino precisamente la necesidad teórica. De ello se infiere también que el principio del cambio periódico no aparece como requisito para la democracia, sino que, por el contrario y en último término, aparece como antitético de la misma. Por lo cual, aunque este enfoque comunista sea equívoco,

* En inglés en el original. 
no se plantea sólo para reavivar barreras históricas, sino sobre todo por agravio intelectual ${ }^{41}$.

Con esta actitud no es sorprendente que el problema constitucional, el problema de quien tiene derecho a gobernar, permanezca todavía sobre el tapete. Las grandes coaliciones de emergencia no siempre implican que haya una solución consesual a la vista, y en el caso italiano, por ejemplo, pueden significar exactamente lo contrario. De hecho, a pesar de todas las transacciones llevadas a cabo hasta ahora, hay un aspecto final de la crisis con el que no se puede transigir, y es justamente quien dirige las coaliciones a la salida de la crisis. Un liderazgo sincrético DC-PCI, del tipo implícito en la propuesta comunista, es totalmente impensable, ya que es obvio que el eje central de una coalición no puede ser ocupado al mismo tiempo por dos fuerzas de parecida consistencia y con claras ambiciones de gobierno. Por tanto, el problema de un liderazgo sincrético es nulo y no negociable. Tampoco es negociable, al menos en un futuro próximo, el paso a un modelo de cambio periódico que rompe con una tradición histórica de sincretismo. Los temores de prevaricación, alimentados por la naturaleza equívoca de la propuesta comunista, hacen de ello una peligrosa opción radicalmente nula.

También es verdad que se ha dejado la puerta cautamente abierta a una evolución democrática del PCI y que, según el parecer de muchos dirigentes democristianos, tal evolución puede ser favorecida por una gestión responsable de la crisis. Pero esta eventualidad sigue siendo hipotética y distante. Por ello, entre tanto, la DC pretende, con los medios a su alcance, posponer y limitar una entrada comunista plena y formal en el campo gubernamental. Por

${ }^{41}$ Algunos políticos han tratado de demostrar recientemente cómo hegemonía y legitimidad democrática pueden reconciliarse. Véase L. Graziano, Historic Compromise and Consociational Democracy: Toward a New Democracy?, ponencia presentada a la convención «The Politics of Mediterranean Europe», International Political Science Association and Greek Political Science Association, Âtenas, 28 de mayo-1 de junio de 1978; P. Lange, The PCI and Possible Outcomes of Italy's Crisis, en L. Graziano y S. Tarrow, La crisi italiana, cit. Por ejemplo, Lange, después de haber discutido las tareas del partido comunista para la defensa de su identidad de partido, para lograr la legitimación democrática y para consolidar la hegemonía como guía en la construcción de un bloque de fuerzas políticas y sociales, continúa del modo siguiente: «... la tensión entre identidad y legitimación... puede ser limitada en la medida en que el partido establece una relación hegemónica eficaz con sus secuaces y con los nuevos aliados. Al establecer una relación de hegemonía, el partido debería estar en condiciones de hacer comprender a secuaces y aliados cómo se relacionan dentro de un esfuerzo estratégico progresivamente compartido. Al hacer esto, el partido crea, naturalmente, una nueva base de consenso entre grupos que se consideraban distintos y supera así la tensión que de otro modo habría resultado de la cohabitación de dos grupos - secuaces y nuevos aliados- dentro del mismo espacio político.»

Pero así establecida la reconciliación de Lange no se aleja mucho de la invocada por los mismos comunistas, implicando una decapitación del dilema legitimidad democrática-hegemonía por vía de definición: la hegemonía, como fenómeno de genuina y común participación, es por eso mismo democrática.

Lo acepten o no los politólogos (por lo que a mí respecta, la participación, aunque sea genuina, es algo muy diferente de la deınocracia), el hecho más importante es que los escépticos son los otros partidos. También a consecuencia de esto la solución política de la crisis no está todavía a la vista. El mismo Lange, por motivos que él explica bien, no considera muy posible una solución hegemónica. En cualquier caso, aunque el PCI ganara la partida, no la ganaría ciertamente por la claridad operativa de su estrategia. El optimismo de la voluntad no niega el también gramsciano pesimismo de la inteligencia. 
otra parte, el hecho de que el PCI siga el juego con un «partner» tan sospechoso y difícil no debería sorprender por más tiempo. Se trata del único juego posible, tan artificioso, por lo demás, que el PCI, con fortuna y habilidad, tiene esperanzas de ganarlo. Podría confortar el hecho de que la realidad ha truncado a menudo otros proyectos hegemónicos, especialmente si son internamente inconsistentes y poco persuasivos, y que unirse al juego democrático, cualesquiera que sean las intenciones, es un modo de convertirse en demócratas. Pero la DC, que ha podido precisamente permitirse una benevolente actitud de espera, está obligada al escepticismo. En efecto, la realidad no le favorece, al menos hasta que el partido no esté en condiciones de ejercitar aquel intangible recurso, la «leadership» que le ha faltado con frecuencia.

En suma, obviamente las extrapolaciones no son posibles, puesto que la crisis, a pesar de las precauciones con que todos han actuado y de las ambiciones comunistas, todavía no proporciona una salida al problema de quién gobierna.

Más modestamente puedo concluir con un augurio basado en algunos hechos. Hay, por lo menos, un punto en el que los democristianos, los socialistas y los otros partidos constitucionales pueden apoyarse para atraer a los comu-

\section{CUADRO 3}

RESULTADO DE LAS ELECCIONES

PARA LA CAMARA DE LOS DIPUTADOS (1946-1976)

(EN PORCENTAJES)

\begin{tabular}{|c|c|c|c|c|c|c|c|c|}
\hline & $1946^{1}$ & 1948 & 1953 & 1958 & 1963 & 1968 & 1972 & 1976 \\
\hline PCI $\ldots \ldots \ldots$ & 18,9 & 310 & 22,6 & 22,7 & 25,3 & 26,9 & 27,2 & 34,4 \\
\hline PSI $\ldots \ldots \ldots$ & $20,7^{3}$ & & 12,7 & 14,2 & 13,8 & $14,5^{4}$ & 9,6 & 9,6 \\
\hline $\begin{array}{lllll}\text { PSDI } & \ldots & \ldots & \ldots \\
\text { PRI } & \ldots & \ldots & \ldots & \ldots \\
\text { DC } & \ldots & \ldots & \ldots & \ldots \\
\text { PLI } & \ldots & \ldots & \ldots & \ldots \\
\text { Monárquicos } & \ldots \\
\text { MSI } & \ldots & \ldots & \ldots & \ldots \\
\text { Mtros } & \ldots & \ldots & \ldots \\
\end{array}$ & $\begin{array}{r}4,4 \\
35,2 \\
6,8 \\
2,8 \\
11,2^{6}\end{array}$ & $\begin{array}{r}7,1 \\
2,5 \\
48,5 \\
3,8 \\
2,8 \\
2,0 \\
2,4\end{array}$ & $\begin{array}{r}4,5 \\
1,6 \\
40,1 \\
3,0 \\
6,9 \\
5,8 \\
2,8\end{array}$ & $\begin{array}{r}4,5 \\
1,4 \\
42,4 \\
3,5 \\
4,8 \\
4,8 \\
1,7\end{array}$ & $\begin{array}{r}6,1 \\
1,4 \\
38,3 \\
7,0 \\
1,8 \\
5,1 \\
1,2\end{array}$ & $\begin{array}{r}2,0 \\
39,1 \\
5,8 \\
1,3 \\
4,5 \\
5,9^{7}\end{array}$ & $\begin{array}{c}5,1 \\
2,9 \\
38,8 \\
3,9 \\
8,7^{5} \\
3,8\end{array}$ & $\begin{array}{r}3,4 \\
3,1 \\
38,7 \\
1,3 \\
6,1 \\
3,4\end{array}$ \\
\hline
\end{tabular}

1 Elecciones para la Asamblea Constituyente.

2 Comunistas y socialistas allados en el Frente Democrático Popular.

3 Soclalistas y socialdemócratas aún unificados en el Partido Socialista Italiano de Unidad Proletaria.

4 Socialistas y socialdemocratas unidos en el Partido Socialista Unificado (PSU).

5 Monárquicos y neofascistas unificados en el MSI-Derecha Nacional.

6 5,2 por 100 al Partido del «Hombre cualquiera»*.

74,5 por 100 al Partido Socialista Italiano de Unidad Proletaria.

- Efímero partido fundado en la inmediata posguerra, que se declaraba apolítico y sin ideología, «simple representante del hombre cualquiera» (l'uomo qualunque). Da origen en el léxico político italiano al término kqualunchismo», todavía vigente, que designa la ideología política del hombre "medio» a quien «no le interesa la política». Con su campaña para desacreditar a todos los partidos, en la que no ocultaba sus simpatías por el fascismo, fue, logicamente, un buen puntal para el neofascismo (del que era en verdad la forma disfrazada que exigía la situación de derrota del fascismo). Como refleja el porcentaje de votos que obtuvo en las elecciones para la Asamblea Constituyente, su Exito, aunque de corta duración, fue notable. (N. del T.) 
nistas a su trama de legitimación. Mientras aquéllos han usado las coaliciones extensas y sin alternancia como recurso, los comunistas están ligados a ellas por una cuestión de principio. Al mismo tiempo, dado el camino ya recorrido y sobre el que pueden verse obligados a seguir recorriendo todavía, es difícil imaginar - tanto en España como en Italia- qué opciones serias quedarían abiertas a los comunistas si tuvieran que rechazar una persuasiva estrategia de alternancia. Por eso, si la colaboración de los comunistas en gobiernos de concentración puede ser correctamente mantenida con fines de emergencia, una cuidadosa estrategia de alternancia, aunque más lejana que en España, no es, sin embargo, impracticable.

Grecia.-También en Grecia, por distintas razones que en Italia, todavía parece difícil predecir la evolución del sistema de partidos y de la fórmula de coalición. En cierto sentido, la crisis abierta por la caída de los coroneles está ya cerrada y no es del todo exacto decir que Grecia está atravesando un período de transición y de búsqueda de futuros reajustes, excepto en el sentido genérico de que toda ordenación política está sujeta a ajustes y cambios. Por otra parte, es demasiado pronto para prever cómo y cuándo los equilibrios de partido pueden alterarse y, sobre todo, cómo responderá exactamente la situación actual. Podemos, sin embargo, encuadrar y prever los principales parámetros de respuesta, que me parecen más rígidos de los disponibles en una ordenación sincrética.

El Gobierno griego ha salido pronto y bien de la fase posterior a la caída de los coroneles, gracias a las ventajas iniciales de una estrategia que, dirigida con firmeza por Karamanlis, le ha permitido monopolizar considerables recursos iniciales, también a través de una ley electoral que favorece a la mayoría de un partido de gobierno, ayudado por una fuerte red de viejas clientelas institucionales, locales y personales. Hay que reconocer al Gobierno griego el mérito de no haberse limitado a una mera ocupación del poder, sino de haber puesto en marcha un proyecto de legalización y legitimación del nuevo orden democrático con pocos precedentes en la historia del país. Pero al igual y aún más que en España, un proceso consciente de legitimación no excluye una posible polarización del sistema de partidos. Diría incluso que en Grecia la polarización de los partidos es hoy una realidad, después de un proceso de inauguración democrática dirigido por el propio Gobierno y dentro de un cuadro institucional gaullista, aborrecido por los extremos comunistas y monárquiconacionalistas y de dudoso valor para el partido socialista. Además un sistema gaullista que tiende, naturalmente, o por norma constitucional, a privilegiar la alternancia a secas, con efectos pendulares agravados por la ley electoral, responde mal a la polarización.

Es decir, si el sistema puede funcionar sin demasiadas sacudidas mientras favorezca al gobierno inicial, existe el peligro de un choque directo en el momento que empiece a favorecer a la oposición, especialmente si ésta rechaza no sólo las convergencias, sino la política y sobre todo el orden de la nueva situación.

Un posible crecimiento del partido socialista, sin una preparación adecuada por parte del nuevo orden, podría por ello crear en Grecia problemas seme- 
jantes a los de Portugal (y a los de Francia en los últimos años) y de más difícil tratamiento en ciertos aspectos (y quiero decir sólo en ciertos aspectos). Como en Portugal, los antagonistas principales serán un partido socialista y uno conservador; pero mientras en Portugal el partido socialista en el gobierno ha encontrado un apoyo moderado en la coalición con el CDS, es difícil prever una alianza gubernamental entre el PASOK y la Unión del Centro. Los socialistas portugueses han sido empujados por los hechos hacia un papel moderado-GARANTISTA. Los socialistas griegos buscan su papel y su imagen, guiados por la misma lógica del sistema gaullista creado por Karamanlis, en una estrategia que todos proclaman de diferenciación no sólo de la derecha, sino también del centro. Aparte de èsto, está el simple hecho del colapso casi total de la Unión del Centro, después de la derrota electoral, la salida de Mavros del partido y la deserción de dos tercios de sus diputados. Lo cual al eliminar un partido comodín, empuja al PASOK y a Nueva Democracia hacia un enfrentamiento. Si después el juego de partidos y coaliciones se asemeja al francés, ello no deja de tener desventajas para Grecia. Del lado de las izquierdas, el sistema griego carece de la capacidad del sistema francés para atraer a los socialistas hacia el centro, como también ha demostrado recientemente ser diferente del portugués aunque por otras razones. Del lado de las derechas, mientras que en Francia la fuerza del cuadro gubernamental no está concentrada en las alas externas del viejo partido gaullista, sino en las internas de los moderados de Giscard d'Estaing y en sus estrategias de atracción, en Grecia no hay indicio, por las razones obvias antes indicadas, de que un papel semejante pueda ser asumido por la Unión del Centro.

En suma, un enfrentamiento en torno al problema de quién tiene derecho a gobernar, y en qué marco institucional, si se pospone no debe ser excluido de ninguna forma, y en esto Grecia carece de los incentivos para arreglos de coalición existentes en otros países del sur de Europa.

CuAdro 4

ELECCIONES PARLAMENTARIAS (NOVIEMBRE 1974 Y 1977)

\begin{tabular}{|c|c|c|c|c|}
\hline & \multicolumn{2}{|c|}{1974} & \multicolumn{2}{|c|}{1977} \\
\hline & $\%$ votos & Escaños & $\%$ votos & Escaños \\
\hline Extrema derecha ${ }^{1} \ldots \ldots \ldots \ldots$ & 1,1 & - & 6,8 & 5 \\
\hline $\begin{array}{llllllll}\text { Nueva } \operatorname{Democracia} & \ldots & \ldots & \ldots & \ldots & \ldots & \ldots & \ldots\end{array}$ & 54,4 & 220 & 41,9 & 172 \\
\hline 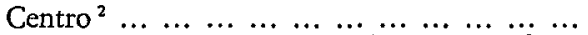 & 20,4 & 60 & 12,0 & 15 \\
\hline Movimiento Socialista Panhelénico (PASOK). & 13,6 & 12 & 25,3 & 93 \\
\hline 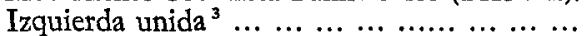 & 9,5 & 8 & - & - \\
\hline 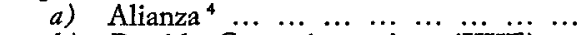 & - & - & 2,7 & 2 \\
\hline b) Partido Comunista griego (KKE) ... & - & - & 9,4 & 11 \\
\hline $\begin{array}{lllllllllllll}\text { Otros } & \ldots & \ldots & \ldots & \ldots & \ldots & \ldots & \ldots & \ldots & \ldots & \ldots & \ldots\end{array}$ & 1,0 & - & 1,9 & 2 \\
\hline
\end{tabular}

1 Unión Democrática Nacional (EDE) en 1974; Frente Nacional (EP) en 1977.

2 Unión del Centro-Fuerza Nueva (EKNS) en 1974; Unión del Centro Democrático (EDIK) en 1977

3 Coalición de dos partidos: KKE e Izquierda Democrática Uniđa (EDA), comprendiendo ahora el Partido Comunista Griego del Interior (KKE Esotérico).

4 Alianza de las Fuerzas Progresistas y de izquierda (KKE Esotérico, EDA, tres grupos minoritarios).

NoтA.- - La distribución de escaños ha sido cambiada ligeramente en las dos elecciones por sentencia de la Magistratura. 


\section{A MODO DE CONCLUSION}

Existen convergencias y temas recurrentes en la historia política de Europa del Sur, pero hay también ocasiones en las que la historia puede sufrir una desviación. De uno de estos momentos somos hoy testigos. Si este ensayo ha conseguido un objetivo, espero precisamente que haya convencido de la importancia de que se estudien ocasiones semejantes.

Traducción: SANTIAgo SáNCHEZ GoNZÁLEZ 